\title{
Individual- and community-level correlates of cigarette-smoking trajectories from age 13 to 32 in a U.S. population-based sample
}

\author{
Bernard Fuemmeler ${ }^{1,2}$, Chien-Ti Lee ${ }^{1}$, Krista W. Ranby ${ }^{3}$, Trenette Clark $^{4}$, F. Joseph \\ McClernon $^{5,6}$, Chongming Yang ${ }^{3}$, and Scott H. Kollins ${ }^{5}$ \\ ${ }^{1}$ Duke University Medical Center, Department of Psychology and Neuroscience, Durham, NC \\ ${ }^{2}$ Duke University, Department of Community and Family Medicine, Durham, NC \\ ${ }^{3}$ Duke University, Center for Child and Family Policy, Durham, NC \\ ${ }^{4}$ University of North Carolina at Chapel Hill, School of Social Work, Chapel Hill, NC \\ ${ }^{5}$ Duke University Medical Center, Department of Psychiatry and Behavioral Science, Durham, NC \\ ${ }^{6}$ Durham VAMC Mental Illness Research, Education, and Clinical Center, Durham, NC
}

\begin{abstract}
Background-Characterizing smoking behavior is important for informing etiologic models and targeting prevention efforts. This study explored the effects of both individual- and communitylevel variables in predicting cigarette use vs. non-use and level of use among adolescents as they transition into adulthood.
\end{abstract}

\begin{abstract}
Methods-Data on 14,779 youths (53\% female) were drawn from the National Longitudinal Study of Adolescent Health (Add Health); a nationally representative longitudinal cohort. A cohort sequential design allowed for examining trajectories of smoking typologies from age 13 to 32 years. Smoking trajectories were evaluated by using a zero-inflated Poisson (ZIP) latent growth analysis and latent class growth analysis modeling approach.
\end{abstract}

\begin{abstract}
Results-Significant relationships emerged between both individual- and community-level variables and smoking outcomes. Maternal and peer smoking predicted increases in smoking over development and were associated with a greater likelihood of belonging to any of the four identified smoking groups versus Non-Users. Conduct problems and depressive symptoms during adolescence were related to cigarette use versus non-use. State-level prevalence of adolescent smoking was related to greater cigarette use during adolescence.
\end{abstract}

\footnotetext{
(C) 2013 Elsevier Ireland Ltd. All rights reserved.

Address correspondence to: Dr. Bernard Fuemmeler, Department of Community and Family Medicine and Psychology and Neuroscience, Duke University Medical Center, DUMC 104006, Durham, NC 27710, bernard.fuemmeler@ duke.edu.

Publisher's Disclaimer: This is a PDF file of an unedited manuscript that has been accepted for publication. As a service to our customers we are providing this early version of the manuscript. The manuscript will undergo copyediting, typesetting, and review of the resulting proof before it is published in its final citable form. Please note that during the production process errors may be discovered which could affect the content, and all legal disclaimers that apply to the journal pertain.

Declaration of Interests

None declared.

Contributions

Bernard Fuemmeler designed the study in conjunct with Joseph McClernon and Scott Kollins. Chongming-Yang advised on analyses. Bernard Fuemmeler and Chien-Ti Lee managed the literature searches and summaries of previous related work. Chien-Ti Lee undertook the statistical analysis based on preliminary results from Bernard Fuemmeler. Bernard Fuemmeler completed the first draft of the manuscript and Chien-Ti Lee, Krista Ranby and Trenette Clark helped edit subsequent revisions of the manuscripts. All authors contributed to the editing the final draft of the the manuscript and have approved the final version.
} 
Conclusions-Individual- and community-level variables that distinguish smoking patterns within the population aid in understanding cigarette use versus non-use and the quantity of cigarette use into adulthood. Our findings suggest that efforts to prevent cigarette use would benefit from attention to both parental and peer smoking and individual well-being. Future work is needed to better understand the role of variables in the context of multiple levels (individual and community-level) on smoking trajectories.

\section{Keywords}

Smoking trajectories; zero-inflated Poisson; ZIP; LCGA; National Longitudinal Study of Adolescent Health; Add Health

\section{INTRODUCTION}

Cigarette use typically begins in early adolescence, with established regular use becoming more prevalent as adolescents mature into adulthood (DiFranza et al., 2007). Smoking habits, however, do not develop the same way for every individual. Some adolescents experiment with smoking but do not increase use with age, while others rapidly progress from experimentation to heavy smoking. Recent studies, employing mixture-modeling approaches, have identified different smoking trajectory subgroups according to time of onset and level of use over time. (Abroms et al., 2005; Audrain-McGovern et al., 2004; Bernat et al., 2008; Chassin et al., 2009, 2000; Costello et al., 2008; Karp et al., 2005; Orlando et al., 2004; Pollard et al., 2010; Riggs et al., 2007; White et al., 2002) These studies outline different smoking patterns and provide insight for further analyses of etiologies and potential intervention strategies.

Across the studies mentioned above, the number and patterns of smoking trajectories vary considerably. The variations may reflect differences in sample size, length of follow-up, or relative representativeness of the samples. Smaller sample sizes have typically resulted in the identification of fewer smoking trajectory subgroups (Chassin et al., 2000; White et al., 2002). Following individuals over a longer time span may also affect the trajectories observed. Many extant studies utilized regional community samples with a short window of follow-up rather than nationally representative, longitudinal samples (Chassin et al., 2000; Colder et al., 2001; Orlando et al., 2004; Riggs et al., 2007; White et al., 2002), resulting in findings with potentially limited generalizability.

Cigarette use over time is particularly challenging to model, with difficulties stemming from the non-normal distribution reflected by the majority of the people abstaining from cigarette use. One solution is to utilize zero inflated Poisson (ZIP) modeling, which allows for simultaneously estimating both the zero (probability of cigarette use) and count (level of cigarettes typically smoked) components of the outcome. This approach also facilitates a more thorough understanding of smoking patterns by allowing the evaluation of covariate effects on each of the two dynamic processes. Extending a ZIP model to longitudinal data by using a latent growth modeling (LGM) approach is well suited for analyzing count data in epidemiologic studies, such as smoking over time (Liu and Powers, 2007).

With respect to correlates of smoking, a social-ecological model proposed by Wilcox (2003) highlights the importance of both individual- and community-level variables as important predictors of youth smoking trajectories. At the individual level, depressive symptoms (Brook et al., 2006; Prinstein and La Greca, 2009), decreased self-efficacy (Hiemstra et al., 2011), impulsivity (Flory and Manuck, 2009), conduct problems (Upadhyaya et al., 2002), number of friends who smoke (Abroms et al., 2005; Ali and Dwyer, 2009; Costello et al., 2008; Hoffman et al., 2007; Karp et al., 2005; Vitaro et al., 2004; White et al., 2002), and 
parental smoking (Gilman et al., 2009; Paul et al., 2008; Villanti et al., 2011; Vitaro et al., 2004; White et al., 2002) have each been linked to increased cigarette use. At the community-level, factors such as tobacco advertising (Sargent et al., 2000), smoking policies (Bernat et al., 2008), cigarette price/taxation (Liang and Chaloupka, 2002), and percentage of adolescent smokers in the community (Lovato et al., 2010) are also predictive of smoking. Yet, little is known about the unique or combined effects of individual- and community-level correlates in predicting smoking trajectories (Wilcox, 2003). Thus, it is not yet fully understood which sets of variables (individual- vs. community-level) are principally predictive of the developmental progression of smoking, whether the relationships between individual-level variables and smoking outcomes differ as a function of different community variables, and to what extent these variables can be used to differentiate smoking trajectory subgroups.

The present study aimed to build upon previous research by examining the effects of individual- and community-level variables on smoking trajectories over development from adolescence to young adulthood in a nationally representative database with a more integrated approach. Thus, the current study set out to (1) describe overall smoking development and identify distinct developmental trajectories of cigarette use in a nationally representative cohort, (2) examine individual- and community-level variables and assess whether these variables are differentially associated with smoking trajectories or developmental subgroups, and 3) examine two-way interactions between individual- and community-level variables in predicting smoking trajectories or developmental subgroups.

\section{Methods}

\subsection{Data Source and Study Sample}

The study population was drawn from 20,774 adolescents in the National Longitudinal Study of Adolescent Health (Add Health), a nationally representative longitudinal cohort. Respondents completed in-home surveys in 1995 and up to 3 additional times (1996, 2001-2002, 2008-2009). The mean ages of the participants at each of the four waves of data collection were $15.65(S D=1.75), 16.22(S D=1.64), 22.96(S D=1.77)$, and $28.9(S D=$ 1.76), respectively. To ensure the data was nationally representative, the Add Health survey was stratified by geographic region, urban versus rural residence, school type, school ethnic diversity, and school size. Study design and data collection have been described elsewhere (Harris et al., 2009; Resnick et al., 1997). The number of participants from the longitudinal cohort who met the minimum criteria for inclusion (were interviewed at least at both Wave I and Wave IV and had available sampling weights) was limited to 14,779 (71.1\% of full sample). Due to missing covariate data, particularly in parent reported education level (missing $n=2,094$ ) and maternal smoking (missing $n=869$ ), our analysis sample was further reduced to 11,639. Compared to participants in the study sample, participants in the analysis sample were similar with respect to parental education level (college vs. no college) and sex. Those included in the analysis sample were more likely to be Caucasian $\chi^{2}=$ 144.11, Cramer's V $=0.10, p<.001$ ) and live in a dual parent KRXVHKROG $\chi^{2}=301.52$, Cramer's $V=0.14, p<.001$ ); however, these differences were small (i.e., effect sizes $<0.3$ ).

\subsection{Measures}

2.2.1 Dependent variable-At all waves, participants reported their smoking status using a computer aided survey instrument (CASI). The smoking variable in the current analyses represents the average number of cigarettes smoked per day, limited to the days the participant smoked, in the past 30 days at each wave. Participants who had never smoked or who had not smoked during the past 30 days were coded as zero and were included in the analyses. 


\subsubsection{Individual-level variables}

Conduct problems: Participants were asked about their level of engagement in 13 conduct problem related behaviors (e.g., property damage, lying to guardians, fighting, number of truancies from school) at Wave I. The 13 items were dichotomized into 0 (never) and 1(1 or more) and then summed. The scale exhibited adequate reliability $(\mathrm{KR}-20=.69)$ and has been used in previously published studies with this sample (Kollins et al., 2005; McClernon et al., 2008).

Depressive symptoms: A modified version of the Center for Epidemiologic Studies Depression (CES-D; Crockett et al., 2005) scale was used to assess depressive symptomatology at Wave I. Respondents were asked to indicate how often they experienced any of 20 depressive symptoms in the past seven days (e.g., you felt depressed). Eighteen items had a response option ranging from 0 (never or rarely) to 3 (most or all of the time). Two other items had a 5-point response scale, which ranged from 0 (never) to 4 (every day). Following previous methods with this scale (Crockett et al., 2005), the 5-point items were modified so that a response of 4 was recoded as a 3 and other responses were retained. A mean was created based on the 20 items. Cronbach's alpha was .75.

Peer and maternal smoking: At Wave I, participants were asked how many of their 3 best friends smoked at least one cigarette a day (range $=0-3$ ), and whether or not their resident mother ever smoked cigarettes.

2.2.3 Community-level variables-The Add Health Wave I tobacco contextual database provides a number of community-level variables linked with respondents' identifiers. Home locations for respondents were geo-coded, linking home location to state, county, tract, and block group Census areas, which allows for the utilization of contextual data from many other sources. Data sources used in the Add Health contextual database containing state-level information were tobacco marketing legislation, state cigarette tax, and state prevalence of adolescent smoking.

The presence of tobacco marketing legislation was measured as not present (0) or present (1). The presence of legislation was based on the existence of any or all of the following: the prohibition of tobacco marketing on billboards within 500 feet of schools and/or churches, a mandate of warnings within advertising for smokeless tobacco, and the prohibition of advertising on lottery tickets or video games (Downey and Gardiner, 1996). Due to the methods by which the source was collected, itemized legislative data was unavailable. Excise tax on a pack of cigarettes in 1995 served as the measure of state cigarette tax. Raw values ranged from 2.5 cents (Virginia) to 81.5 cents (Washington). To increase interpretability the 1 cent value was rounded to 25 cent increments. The prevalence of adolescent smoking was drawn from the Youth Risk Behavioral Surveillance survey, which provided the percent of high school students (grades 9-12) in the Add Health participant's state who smoked in 1995. The measure ranged from 3\% to 19.9\% (Kann et al., 1995).

2.2.4 Control variables-To reduce potential confounding by sex, race/ethnicity, socioeconomic status or caregiver burden, the following covariates were included in all models: sex, race/ethnicity (white, Hispanic, African-American, other), parental (or caregivers') education (less than high school, high school or equivalent, some college, and college degree or beyond), and family structure (one versus two parent household).

\subsection{Analytic Strategy}

Analyses were conducted using Mplus version 6.12 (Muthén and Muthén, 1998-2012).

Survey design effects and survey weights were incorporated into the analysis to compensate 
for differences in selection probabilities, differential rates of non-response and attrition, and chance fluctuations between the sample and the population. The application of survey weights helps the Add Health sample by approximating the composition of U.S. population as closely as possible within the given confines of the data.

2.3.1 Latent growth modeling of changes in smoking - LGM with ZIP was used to model patterns of developmental changes in smoking among youths during Wave I (minimum age of 13) through Wave IV (maximum age of 32). LGM allows for estimating the average level of a parameter at a point in time (i.e., intercept), the rate of increase/ decrease over time (i.e., linear trend), and the rate of change in the increase/decrease (i.e., quadratic trend; Bollen and Curran, 2006; Duncan and Duncan, 2004). These growth components can be regressed on covariates to determine the association of a particular covariate with each growth component. A cohort-sequential design was employed, in which age, rather than wave of assessment, was the unit of time (Bollen and Curran, 2006; Duncan et al., 2006, 2007). Individual Add Health respondents contributed up to four repeated observations of smoking. Due to age overlap, an adequate number of participants at 20 discrete ages were available, and thus, it was possible to model the smoking trajectory from age 13 to 32. Using this design results in substantial amounts of missing data, however, Mplus employs an expectation maximization (EM) algorithm to limit potential biases in such designs (Duncan et al., 2006).

To start, a series of unconditional models were evaluated to determine whether the smoking trajectories were best represented by a linear only or a linear and quadratic growth function. Within this LGM framework, ZIP was used to simultaneously estimate binary (probability of cigarette use) and count (number of cigarettes smoked among those who smoked) components of the smoking trajectories. The count component of the smoking outcome is referred to as "the level of smoking" throughout the analysis and discussion. Both binary and count growth components were regressed on the covariates which included control variables, individual-, and community-level variables. We also examined two-way interactions between individual- and community-level correlates with significant main effects in the model.

\subsubsection{Latent class growth analysis of smoking trajectory subgroups-}

Subsequent to fitting the LGM, a LCGA with ZIP was used to estimate smoking trajectory subgroups. LCGA is a semi-parametric group-based approach that assumes unobserved population heterogeneity in smoking and change in smoking over time. This data-driven approach produces a latent categorical class variable for each individual, with distinct categories representing each subgroup (Li et al., 2001). The Bayesian Information Criterion (BIC; Schwarz, 1978) is used as the primary fit statistic to evaluate whether a given model with a certain number of classes fits the data better than a nested model with one fewer class. Additionally, entropy, parsimony, and substantive interpretability are also used to evaluate the results. Models with lower Bayesian Information Criteria values, higher entropy, parsimony, and substantive interpretability are preferred (Connell et al., 2006; Muthén and Muthén, 2000). After we established the best-fitting growth-mixture model, the association between the individual- and community-level variables and smoking subgroups were examined via multinomial logistic regression. This was done within Mplus by utilizing 20 pseudo draws based on posterior probabilities of group membership for each individual. For these results, the non-smoking subgroup served as the referent subgroup (Clark and Muthén, 2009). 


\section{RESULTS}

\subsection{Descriptive Statistics}

Approximately half $(53 \%)$ of the sample $(N=11,639)$ was female. The largest race/ethnic group was non-Hispanic White (56\%), followed by Black (20\%), Hispanic (16\%), and Other $(8 \%)$. Seventy-two percent of respondents lived in a two-parent household, and $24 \%$ of primary caregivers had a college degree or higher. Forty seven percent of participants had a mother figure that ever smoked, and $43 \%$ of the sample reported at least one friend who smoked. The mean level of depressive symptoms at baseline was .61 $(S D=.40$, range 0 to $2.85)$ and conduct problems was $.89(S D=1.39$, range 0 to 10$)$.

\subsection{Latent Growth Modeling of Changes in Smoking}

Because the simulated cohort begins at age 13, this age was set as the intercept for all models in the current study. This age corresponds to the peak age of cigarette initiation (Johnston et al., 2008). A significant chi-square difference test statistic using Satorra-Bentler scaled chi-square (Satorra and Bentler, 2001) indicated that the model with linear and quadratic latent growth components was a better fit than the model with only a linear growth component, $\Delta \chi^{2}(2)=433.15, p<.001$. Figure 1-A represents the unconditional growth model for the binary trajectory - the estimated prevalence of smoking a cigarette. Figure 1-B represents the unconditional growth model for the count trajectory - estimated mean number of cigarettes smoked among those who ever smoked a cigarette.

For the unconditional LGM, all growth parameters were significant at $p<.001$ levels, Loglikelihood $=-96,259.98$, AIC $=192,531.96$, and BIC $=192,573.13$. The intercept for the binary trajectory was $-1.29(S E=.06)$ which suggests that the probability of smoking a cigarette at age 13 was $0.22\left(\mathrm{p}(\right.$ smoking $) /[1-\mathrm{p}($ smoking $\left.)]=\mathrm{e}^{-1.29}\right)$. The prevalence of smoking increased with age, as indicated by a significant positive linear slope $(b=1.68, S E$ $=.12$ ) and the increase in the change in smoking decelerated approaching adulthood, as indicated by a negative quadratic slope $(b=-.77, S E=.07)$. For the count trajectory, the intercept of the level of cigarettes smoked among those that smoked was $1.50(S E=.06)$, which is approximately $1\left(\mathrm{e}^{1.50 * 0.22=0.99)}\right.$ cigarette on a smoking occasion. The significant positive linear slope showed the level of cigarette use increased with age ( $b=$ $1.71, S E=.12)$. The significant negative quadratic effect $(b=-.71, S E=.06)$ indicated a deceleration in the increasing level of cigarette use from adolescence to adulthood.

The conditional LGM included sex, race/ethnicity, parental education, family structure, and each of the individual- and community-level variables listed in Table 1 (Log-likelihood= $-85,833.06, \mathrm{AIC}=171,870.12$, and $\mathrm{BIC}=172,621.05)$. Below, we describe the associations between individual- and community-level variables and the ZIP LGM. To aid interpretation, Figure 2 displays the shape of these growth trajectories for variables that were significant in the model with curves plotted for null ( 0 ) and positive cases (1 or 1 or greater) for each variable.

Having more friends who smoked, greater conduct problems, and higher depressive symptoms at baseline were related to a greater probability of smoking at age 13 ( $b=.73, b$ $=.38, b=.15$, respectively). These individual-level variables were also significantly related to a slower increase in cigarette use versus non-use over time $(b=-.60, b=-.35, b=-.24$, respectively). Additionally, having more friends who smoked, greater conduct problems, and higher depressive symptoms were associated with positive quadratic parameters ( $b=$. $53, b=.31, b=.28$, respectively). This indicates that the deceleration in the change in the probability of cigarette use was less pronounced for individuals who had these characteristics at the initial assessment (Wave 1). Although maternal smoking was not associated with the intercept of cigarette use, adolescents who reported that their mother 
smoked had a more rapid increase in the probability of cigarette use over time $(b=.26)$; however, the rate of deceleration in the probability of smoking was more pronounced over development $(b=-.29)$. With respect to community-level variables, state prevalence of adolescents smoking was associated with a greater increase in probability of cigarette use over time $(b=.15)$.

Maternal smoking and peer smoking were significantly related to higher levels of cigarettes smoked at age 13 ( $b=.25, b=.63$, respectively). Relative to the increasing trend of smoking, maternal and peer smoking were significantly associated with lower rates of increase $(b=-.32, b=-.67)$. Compared to having a mother who smoked, the deceleration in this increase in smoking was less pronounced for those who had friends who smoked $(b=$. 60 vs $b=.33$ ). Of the community-level variables state prevalence of adolescent smoking was only significantly related to cigarettes smoked at age $13(b=.16)$. No other significant associations between community-level variables and smoking trajectory components were found.

Since state prevalence of adolescent smoking was the only significant community-level variable related to either the binary or level of smoking, interactions terms between this variable and the individual-level variables were formed. In models with the main effects, there were no significant two-way interactions of individual-level correlates (maternal smoking, peer smoking, depression, and conduct problems) with state prevalence of adolescents smoking identified.

\subsection{Latent Class Growth Analysis of Smoking Trajectory Subgroups}

The fit of the unconditional growth mixture models for zero-inflated count data with 1-6 classes were compared. All models included the mean factor of intercept, slope, and quadratic slope. Comparing BIC indices across models, a five-class model (133120.46) and six-class model (130825.70) exhibited similar fit; however, a five-class model produced a higher entropy (.847) value, which indicates a better classification of participants. Further, given the similar fit indices, the more parsimonious 5-class model is preferable. Analyses were continued using the 5-class specification. The smoking trajectory pattern for each class (subgroup) is presented in Figure 3.

The smoking typology was loosely labeled as Non-Users (54\%), Light Users (18\%), Early Users (10\%), Late Users (16\%), and Late Heavy Users (2\%). The names of these classes are derived from their respective trajectory patterns. Non-users are characterized as those who have never smoked or having smoked zero cigarettes in the 30 days preceding each wave. Light Users are those who smoked at a low level throughout development (i.e., $<5$ cigarettes). Early users exhibit an established pattern of smoking at Wave 1. Late Users and Late Heavy Users both demonstrate low rates of smoking until the late teens, after which the smoking rates of both classes show steady increases, with the rate of increase among Late Heavy Users being significantly greater.

Table 2 presents the results of the individual- and community-level variables on smoking trajectory subgroups after controlling for sex, race/ethnicity, parental education, family structure, and each of the individual- and community-level factors. Maternal smoking, greater numbers of friends who smoke, and more conduct problems were significantly associated with being in any smoking subgroup when compared to Non-Users. Having a mother who smoked was associated with nearly a two-fold increase in the likelihood of being an Early User versus a Non-User $(\mathrm{OR}=1.83)$. Additionally, being affiliated with friends who smoked increased the likelihood of being an Early User versus a Non-User. In follow-up testing across five pseudo-classes using posterior probability-based multiple imputations, Early Users had the highest mean number of friends who smoked ( $M=1.61$; 
$S E=.04)$, followed by Late Heavy Users $(M=1.24 ; S E=.09)$, Late Users $(M=1.19 ; S E$

$=.03)$, Light Users $(M=0.89 ; S E=.03)$, and Non-Users $(M=.48 ; S E=.01)$. Although there were no significant differences in numbers of friends who smoked between Late Users and Late Heavy Users, statistically significant differences were observed between other subgroup pairs.

Being categorized into any of the four smoking subgroups was significantly associated with a greater prevalence of adolescent smoking in the states where participants lived. No twoway interaction effects between each pair of individual-level correlate and prevalence of adolescent smoking in the state were observed.

\section{DISCUSSION}

This study described smoking trajectories of initial cigarette use and level of use from adolescence to early adulthood. In addition, five cigarette-smoking patterns were identified: Non-Users, Light Users, Early Users, Late Users, and Late Heavy Users. Notably, the Early Users and the Late Heavy Users had different patterns over development; however, they tended to look similar in later adulthood with respect the number of cigarettes smoked. The same can be said of the Late Users and Light Users. Several of the individual-level variables in our model (e.g., maternal smoking, peer smoking, conduct problems, depressive symptoms) were associated with the overall trajectories of cigarette use and levels of use among smokers in the population. They were also significant in distinguishing Non-Users from other smoking subgroups. Community-level factors (i.e., prevalence of smoking in the state, tobacco marketing policies/taxes) were less consistently related to smoking outcomes in the models that also included individual-level variables. However, we did find that smoking initiation increased more rapidly over development in states with a higher adolescent smoking prevalence. Together, the study highlights the importance of considering individual- and community-level variables jointly in adolescent smoking trajectories.

Results from ZIP growth curve models revealed that the prevalence of cigarette use is fairly low during early adolescence (age 13), but increases rapidly throughout adolescence, with the rate of this increase slowing during adulthood. In line with a wealth of literature, our findings show that smoking initiation typically begins during adolescence (Chassin et al., 2009; Gilman et al., 2009; Nelson et al., 2008; Vitoria et al., 2011), nevertheless, our findings are unique in describing how the rate of increase in initial cigarette use changes across adolescence and early adulthood development. Using a slightly different methodology, Messer and Pierce (2010) showed a somewhat similar pattern of first smoking experimentation analyzing data from the California Tobacco Survey. Similar to what we found, they report an increase in experimentation from age 12 to young adulthood with little new experimentation after age 22 or 23 (Messer and Pierce, 2010). With respect to the estimated mean of the number of cigarettes smoked, the mean increased through adolescence, peaked during the mid-twenties, after which it leveled off and then slightly decreased thereafter.

Predictors of trajectories of cigarette use were not necessarily the same as predictors of the level of cigarettes smoked. Similar to what has been reported in other studies (Prinstein and La Greca, 2009; Upadhyaya et al., 2002), depressive symptoms and conduct problems at Wave 1 were associated with a higher likelihood of cigarette use. These same factors were not predictive of level of cigarettes smoked. Also, state prevalence of adolescent smoking related to a greater increase in probability of cigarette use but only predicted a higher starting point of the level of cigarettes smoked. Other factors like peer and maternal smoking were related to both the trajectories of cigarette use and the level of cigarettes smoked. 
These findings suggest that efforts to prevent the initiation of cigarette use should incorporate the relevance of parental and peer smoking, as well as individual-level psychological variables. The state prevalence of adolescent smoking may also be a relevant factor to consider when initiating such prevention efforts, as more intensive efforts may be needed in states with a higher smoking prevalence.

The current results also show that while many variables were related to smoking trajectories, the strengths of associations differed among smoking subgroups. For instance, compared to Non-Users members of the smoking subgroups were all more likely to indicate they had friends who smoked at baseline, but this relationship was particularly strong among Early Users (e.g., an OR of 2.2 vs. ORs between 1.4 - 1.7). Likewise, a significant relationship was found between each of the smoking subgroups and the prevalence of adolescents smoking in the state, though, in this case, the association was pronounced in the Late Heavy Users. These findings suggest that members of particular smoking subgroups (Early Users or Late Heavy Users) have different levels of risk based on presence of individual- and community-level variables.

The scope of current study focused on potential variables during early adolescence, namely at Wave 1, that may be associated with smoking development from adolescence through adulthood. However, many of these variables likely change over time, which may have led to us underestimating the true effect. Assessing these variables as time-varying covariates would be the next logical step. It should also be recognized that while temporal relationships between variables were evaluated, causal associations cannot be determined. There may be a number of unmeasured confounding effects that may be relevant to these associations. However, we did attempt to control for factors related to race, sex, socio-economic status, and caregiver burden. As is also the case with epidemiologic investigations, the mechanisms through which these associations operate cannot be determined with certainty. Finally, the null effects of the community-level variables should not be interpreted to mean that community-level variables are irrelevant or less important than individual-level variables. Our analysis was limited to only three community-level variables. Other factors, such as limiting sale in vending machines, tobacco law enforcement programs or state funds appropriated for tobacco control may also be important community-level variables relevant to adolescent smoking trajectories and could be assessed in future studies.

Despite these caveats, this study does add new information. By combining the newly released Wave IV data from Add Health with the data from the previous waves, our findings help better elucidate smoking trajectories over a longer developmental period and verify the role of relevant predictors on these smoking trajectory outcomes. Additionally, few studies have simultaneously examined the effects of individual- and community-level correlates on smoking trajectories and subgroups (Wilcox, 2003). Overall, given the relative importance of peer smoking, depressive symptoms, conduct problems, and state prevalence of adolescent smoking on cigarette initiation, it is recommended that future studies assess the effects of these factors in a time-varying fashion and examine potentially meaningful mediation and/or interaction effects. Additional research is also needed to examine the risk factors in the context of competing risks for multiple substance initiation and use.

\subsection{Conclusions}

Studies, such as this one, highlight the importance of considering the smoking phenotype as a developmental pattern for which there are changes in initial cigarette use over time, changes in level of use among those that smoke, and varying trajectory subgroups. The causes of smoking can be better understood by the identifying individual- and communitylevel variables that relate to changes in smoking initiation or the rate of accelerations in smoking. Continued epidemiologic work is needed that can consider variables at different 
levels over the course of development if we are to make progress at identifying optimal ways for preventing smoking in our society.

\section{Acknowledgments}

The authors thank Kevin Prybol, for assisting with the preparation and proof-reading of the manuscript, and thank the Add Health research team for providing us with the data necessary for our analysis.

\section{Funding}

This research uses data from Add Health, a program project directed by Kathleen Mullan Harris and designed by J. Richard Udry, Peter S. Bearman, and Kathleen Mullan Harris at the University of North Carolina at Chapel Hill, and funded by grant P01-HD31921 from the Eunice Kennedy Shriver National Institute of Child Health and Human Development, with cooperative funding from 23 other federal agencies and foundations. Special acknowledgment is due Ronald R. Rindfuss and Barbara Entwisle for assistance in the original design. Information on how to obtain the Add Health data files is available on the Add Health website (http://www.cpc.unc.edu/addhealth). No direct support was received from grant P01-HD31921 for this analysis.

Support to complete analyses and writing this manuscript was received from the following NIH grants: R01 DA030487 awarded to BFF, R01 DA030487 S awarded to BFF to support TC, 1K07CA124905 awarded to BFF, K24 DA023464 awarded to SHK. For her work on this manuscript, KWR was supported in part by NIDA Grant P30 DA023026. Its contents are solely the responsibility of the author(s) and do not necessarily represent the official views of NIH or NIDA.

\section{REFERENCES}

Abroms L, Simons-Morton B, Haynie DL, Chen RS. Psychosocial predictors of smoking trajectories during middle and high school. Addiction. 2005; 100:852-861. [PubMed: 15918815]

Ali MM, Dwyer DS. Estimating peer effects in adolescent smoking behavior: a longitudinal analysis. J. Adolesc. Health. 2009; 45:402-408. [PubMed: 19766946]

Audrain-McGovern J, Rodriguez D, Tercyak KP, Cuevas J, Rodgers K, Patterson F. Identifying and characterizing adolescent smoking trajectories. Cancer Epidemiol. Biomarkers Prev. 2004; 13:2023-2034. [PubMed: 15598757]

Bernat DH, Erickson DJ, Widorne R, Perry CL, Forster JL. Adolescent smoking trajectories: results from a population-based cohort study. J. Adolesc. Health. 2008; 43:334-340. [PubMed: 18809130]

Bollen, KA.; Curran, PJ. Latent Curve Models: A Structural Equation Perspective. Wiley-Interscience; Hoboken, NJ: 2006.

Brook JS, Ning YM, Brook DW. Personality risk factors associated with trajectories of tobacco use. Am. J. Addiction. 2006; 15:426-433.

Chassin, L.; Curran, PJ.; Presson, CC.; Sherman, SJ.; Wirth, R., editors. Developmental Trajectories of Cigarette Smoking from Adolescence to Adulthood. US Department of Health and Human Services, National Institutes of Health, National Cancer Institute; Bethesda, MD: 2009.

Chassin L, Presson CC, Pitts SC, Sherman SJ. The natural history of cigarette smoking from adolescence to adulthood in a midwestern community sample: multiple trajectories and their psychosocial correlates. Health Psychol. 2000; 19:223-231. [PubMed: 10868766]

Clark, S.; Muthén, B. Relating Latent Class Analysis Results to Variables Not Included in the Analysis. 2009. http://www.statmodel.com/download/relatinglca.pdf.accessed

Colder CR, Mehta P, Balanda K, Campbell RT, Mayhew KP, Stanton WR, Pentz MA, Flay BR. Identifying trajectories of adolescent smoking: an application of latent growth mixture modeling. Health Psychol. 2001; 20:127-135. [PubMed: 11315730]

Connell AM, Dishion TJ, Deater-Deckard K. Variable-and person-centered approaches to the analysis of early adolescent substance use: linking peer, family, and intervention effects with developmental trajectories. Merrill-Palmer Quarterly: Journal of Developmental Psychology. 2006; 52:421-448.

Costello DM, Dierker LC, Jones BL, Rose JS. Trajectories of smoking from adolescence to early adulthood and their psychosocial risk factors. Health Psychol. 2008; 27:811-818. [PubMed: 19025277] 
Crockett LJ, Randall BA, Shen YL, Russell ST, Driscoll AK. Measurement equivalence of the Center for Epidemiological Studies Depression Scale for Latino and Anglo adolescents: a national study. J. Consult. Clin. Psych. 2005; 73:47-58.

DiFranza JR, Savageau JA, Fletcher K, O’Loughlin J, Pbert L, Ockene JK, McNeill AD, Hazelton J, Friedman K, Dussault G, Wood C, Wellman RJ. Symptoms of tobacco dependence after brief intermittent use - the development and assessment of nicotine dependence in youth-2 study. Arch. Pediatr. Adolesc. Med. 2007; 161:704-710. [PubMed: 17606835]

Downey, LA.; Gardiner, JA. Reducing Youth Access to Tobacco: A Partial Inventory of State Initiatives. University of Illinois at Chigago, Office of Social Science Research; Chicago: 1996.

Duncan SC, Duncan TE, Strycker LA. Alcohol use from ages 9 to 16: a cohort-sequential latent growth model. Drug Alcohol Depend. 2006; 81:71-81. [PubMed: 16006054]

Duncan SC, Duncan TE, Strycker LA, Chaumeton NR. A cohort-sequential latent growth model of physical activity from ages 12 to 17 years. Ann. Behav. Med. 2007; 33:80-89. [PubMed: 17291173]

Duncan TE, Duncan SC. An introduction to latent growth curve modeling. Behav. Ther. 2004; 35:333-363.

Flory JD, Manuck SB. Impulsiveness and cigarette cmoking. Psychosom. Med. 2009; 71:431-437. [PubMed: 19251874]

Gilman SE, Rende R, Boergers J, Abrams DB, Buka SL, Clark MA, Colby SM, Hitsman B, Kazura AN, Lipsitt LP, Lloyd-Richardson EE, Rogers ML, Stanton CA, Stroud LR, Niaura RS. Parental smoking and adolescent smoking initiation: an intergenerational perspective on tobacco control. Pediatrics. 2009; 123:E274-E281. [PubMed: 19171580]

Harris, K.; Halpern, C.; Whitsel, E.; Hussey, J.; Tabor, J.; Entzel, P.; Udry, J. The National Longitudinal Study of Adolescent Health: Research Design. North Carolina Population Center; Chapel Hill: 2009.

Hiemstra M, Otten R, de Leeuw RNH, van Schayck OCP, Engels RCME. The changing role of selfefficacy in adolescent smoking initiation. J. Adolesc. Health. 2011; 48:597-603. [PubMed: 21575820]

Hoffman BR, Monge PR, Chou CP, Valente TW. Perceived peer influence and peer selection on adolescent smoking. Addict. Behav. 2007; 32:1546-1554. [PubMed: 17188818]

Johnston, LD.; O’Malley, PM.; Bachman, JG.; Schulenberg, JE. Monitoring the Future National Survey Results on Drug Use, 1975-2007. Volume I: Secondary School Students (NIH Publication No. 08-6418A). National Institute on Drug Abuse; Bethesda, MD: 2008.

Kann L, Warren CW, Harris WA, Collins JL, Douglas KA, Collins ME, Williams BI, Ross JG, Kolbe LJ. Youth risk behavior surveillance - United-States, 1993. J. School Health. 1995; 65:163-171. [PubMed: 7637332]

Karp I, O’loughlin J, Paradis G, Hanley J, Difranza J. Smoking trajectories of adolescent novice smokers in a longitudinal study of tobacco use. Ann. Epidemiol. 2005; 15:445-452. [PubMed: 15967392]

Kollins SH, McClernon FJ, Fuemmeler BF. Association between smoking and attention-deficit/ hyperactivity disorder symptoms in a population-based sample of young adults. Arch. Gen. Psychiatry. 2005; 62:1142-1147. [PubMed: 16203959]

Li FZ, Duncan TE, Duncan SC, Acock A. Latent growth modeling of longitudinal data: a finite growth mixture modeling approach. Struct. Equ. Modeling. 2001; 8:493-530.

Liang L, Chaloupka FJ. Differential effects of cigarette price on youth smoking intensity. Nicotine Tob. Res. 2002; 4:109-114. [PubMed: 11906687]

Liu H, Powers DA. Growth curve models for zero-inflated count data: an application to smoking behavior. Struct. Equ. Modeling. 2007; 14:247-279.

Lovato CY, Zeisser C, Campbell HS, Watts AW, Halpin P, Thompson M, Eyles J, Adlaf E, Brown KS. Adolescent smoking: effect of school and community characteristics. Am. J. Prev. Med. 2010; 39:507-514. [PubMed: 21084070]

McClernon FJ, Fuemmeler BF, Kollins SH, Kail ME, Ashley-Koch AE. Interactions between genotype and retrospective ADHD symptoms predict lifetime smoking risk in a sample of young adults. Nicotine Tob. Res. 2008; 10:117-127. [PubMed: 18188752] 
Messer K, Pierce JP. Changes in age trajectories of smoking experimentation during the California Tobacco Control Program. Am. J. Public Health. 2010; 100:1298-1306. [PubMed: 19965566]

Muthén B, Muthén LK. Integrating person centered and variable centered analyses: growth mixture modeling with latent trajectory classes. Alcohol. Clin. Exp. Res. 2000; 24:882-891. [PubMed: 10888079]

Muthén, L.; Muthén, B. Mplus User’s Guide. Muthén \& Muthén; Los Angeles: 1998-2012.

Nelson DE, Mowery P, Asman K, Pederson LL, O’Malley PM, Malarcher A, Maibach EW, Pechacek TF. Long-term trends in adolescent and young adult smoking in the United States: metapatterns and implications. Am. J. Public Health. 2008; 98:905-915. [PubMed: 18382001]

Orlando M, Tucker JS, Ellickson PL, Klein DJ. Developmental trajectories of cigarette smoking and their correlates from early adolescence to young adulthood. J. Consult. Clin. Psych. 2004; 72:400 410 .

Paul SL, Blizzard L, Patton GC, Dwyer T, Venn A. Parental smoking and smoking experimentation in childhood increase the risk of being a smoker 20 years later: the Childhood Determinants of Adult Health Study. Addiction. 2008; 103:846-853. [PubMed: 18412765]

Pollard MS, Tucker JS, Green HD, Kennedy D, Go MH. Friendship networks and trajectories of adolescent tobacco use. Addict. Behav. 2010; 35:678-685. [PubMed: 20332061]

Prinstein MJ, La Greca AM. Childhood depressive symptoms and adolescent cigarette use: a six-year longitudinal study controlling for peer relations correlates. Health Psychol. 2009; 28:283-291. [PubMed: 19450033]

Resnick MD, Bearman PS, Blum RW, Bauman KE, Harris KM, Jones J, Tabor J, Beuhring T, Sieving RE, Shew M, Ireland M, Bearinger LH, Udry JR. Protecting adolescents from harm. Findings from the National Longitudinal Study on Adolescent Health. JAMA. 1997; 278:823-832. [PubMed: 9293990]

Riggs NR, Chou CP, Li C, Pentz MA. Adolescent to emerging adulthood smoking trajectories: when do smoking trajectories diverge, and do they predict early adulthood nicotine dependence? Nicotine Tob. Res. 2007; 9:1147-1154. [PubMed: 17978988]

Sargent JD, Dalton M, Beach M, Bernhardt A, Heatherton T, Stevens M. Effect of cigarette promotions on smoking uptake among adolescents. Prev. Med. 2000; 30:320-327. [PubMed: 10731461]

Schwarz G. Estimating dimension of a model. Ann. Stat. 1978; 6:461-464.

Upadhyaya HP, Deas D, Brady KT, Kruesi M. Cigarette smoking and psychiatric comorbidity in children and adolescents. J. Am. Acad. Child Psychol. 2002; 41:1294-1305.

Villanti A, Boulay M, Juon HS. Peer, parent and media influences on adolescent smoking by developmental stage. Addict. Behav. 2011; 36:133-136. [PubMed: 20855170]

Vitaro F, Wanner B, Brendgen M, Gosselin C, Gendreau PL. Differential contribution of parents and friends to smoking trajectories during adolescence. Addict. Behav. 2004; 29:831-835. [PubMed: 15135568]

Vitoria PD, Salgueiro MF, Silva SA, de Vries H. Social influence, intention to smoke, and adolescent smoking behaviour longitudinal relations. Br. J. Health Psychol. 2011; 16:779-798. [PubMed: 21988064]

White HR, Pandina RJ, Chen PH. Developmental trajectories of cigarette use from early adolescence into young adulthood. Drug Alcohol Depend. 2002; 65:167-178. [PubMed: 11772478]

Wilcox P. An ecological approach to understanding youth smoking trajectories: problems and prospects. Addiction. 2003; 98(Suppl. 1):57-77. [PubMed: 12752362] 

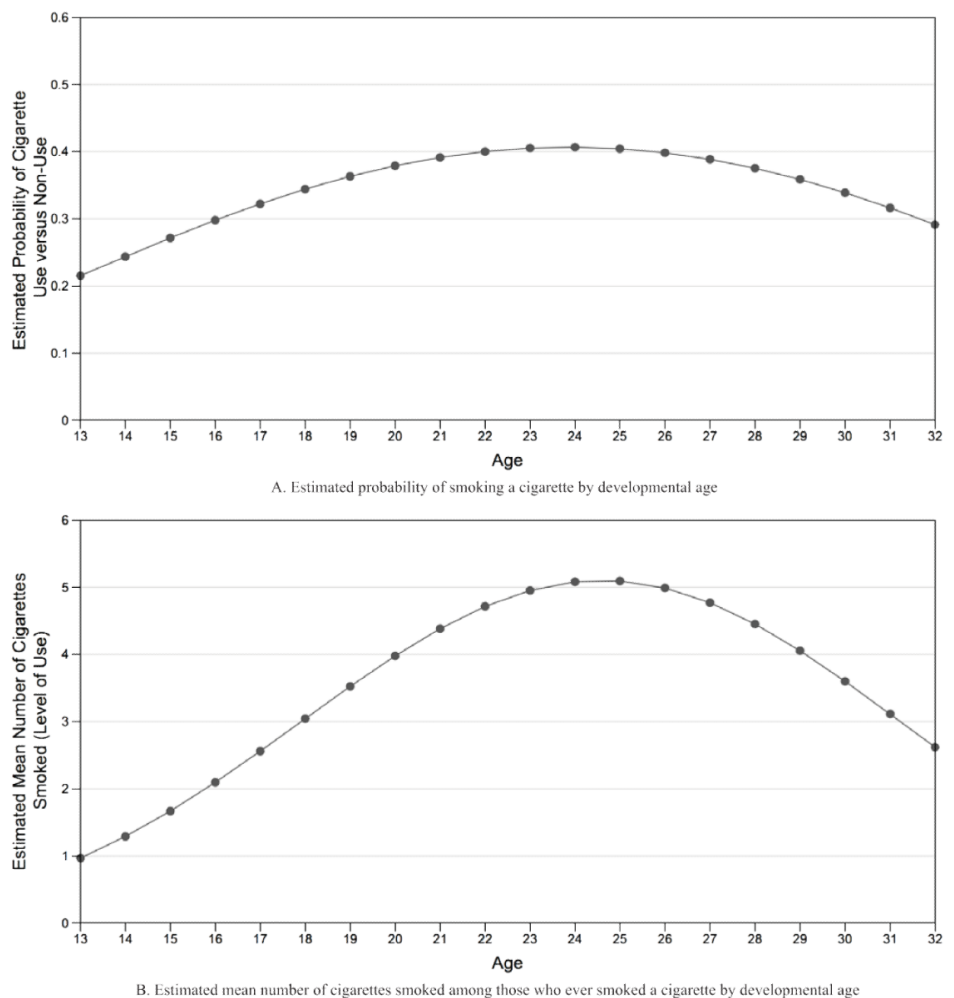

Figure 1.

Smoking trajectories from age 13 to age 32 . 

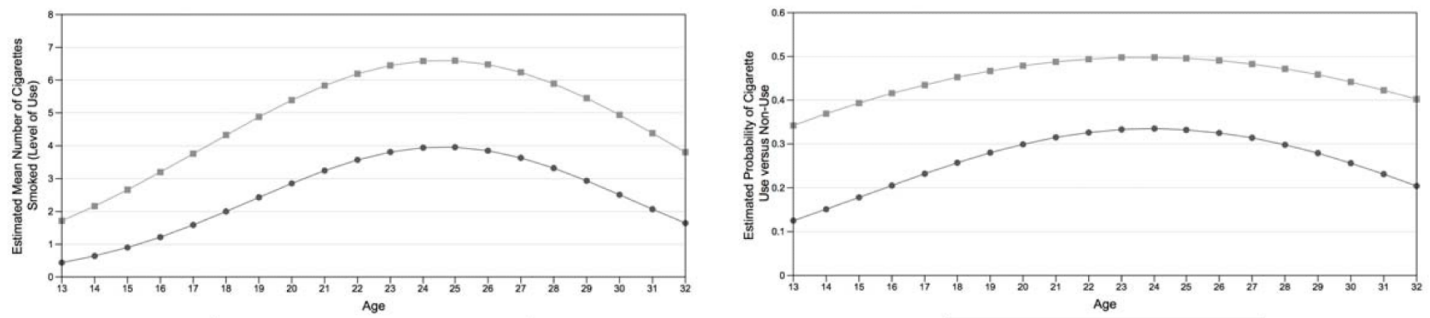

- Conduct Problems $=0$ - Conduct Problems 21
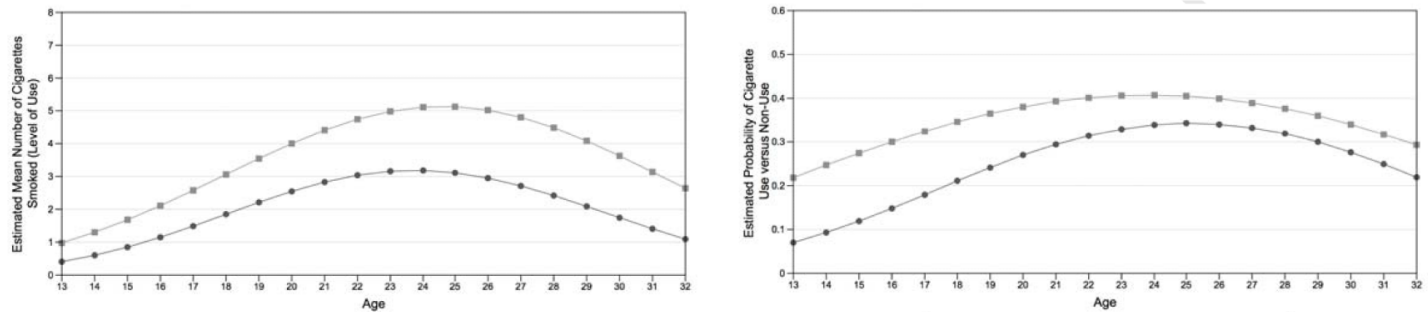

- Depressive Symptoms $=0$ - Depressive Symptoms 21

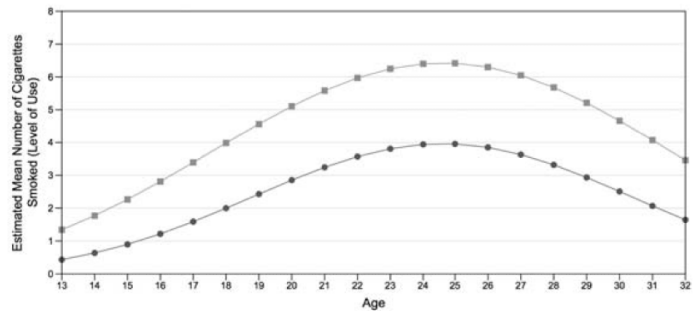

$\rightarrow$ Depressive Symptoms $=0$ - Depressive Symptoms 21

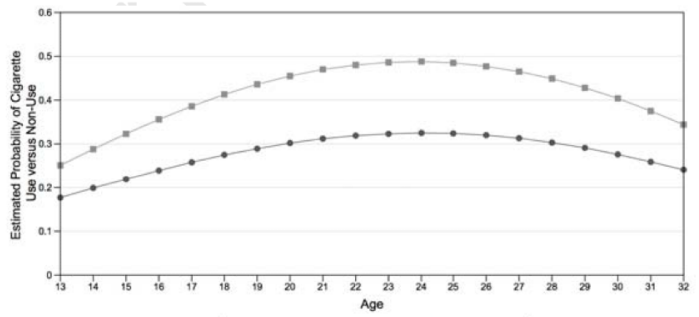

$\rightarrow$ Maternal Smoking $=0 \Rightarrow$ Maternal Smoking $=1$

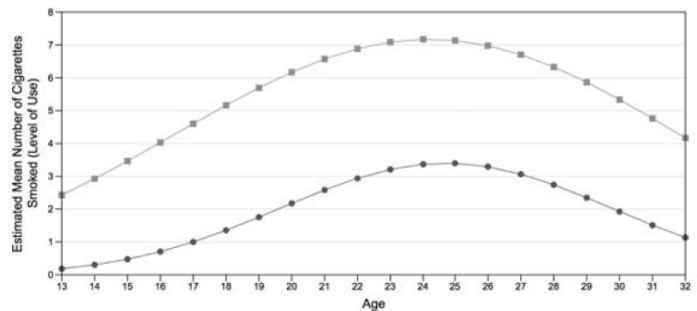

- Matemal Smoking $=0=$ Maternal Smoking 21

- Peer Smoking $=0=$ Peer snoking $z 1$
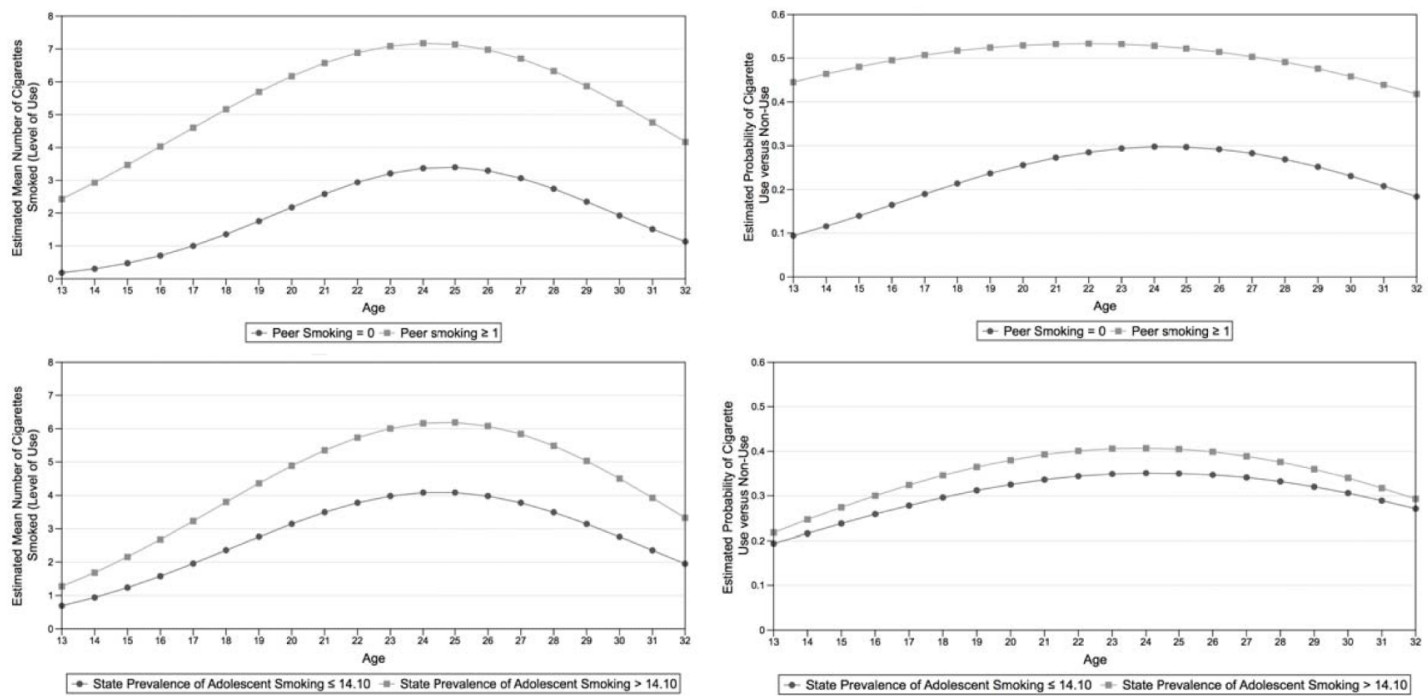

- Peer Smoking $=0$ - Peer smoking 21

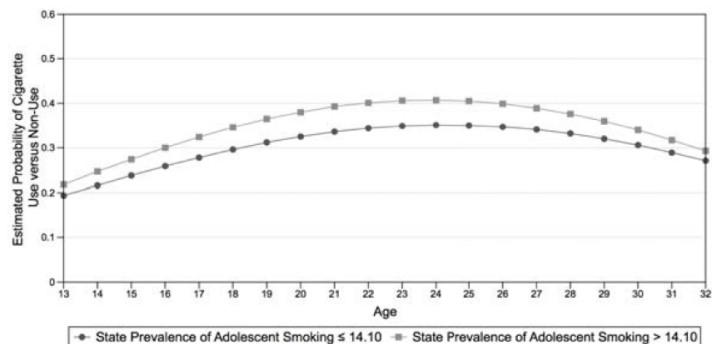

Figure 2.

Probabilities and rates of smoking for individual- and community-level variables with significant effects. 


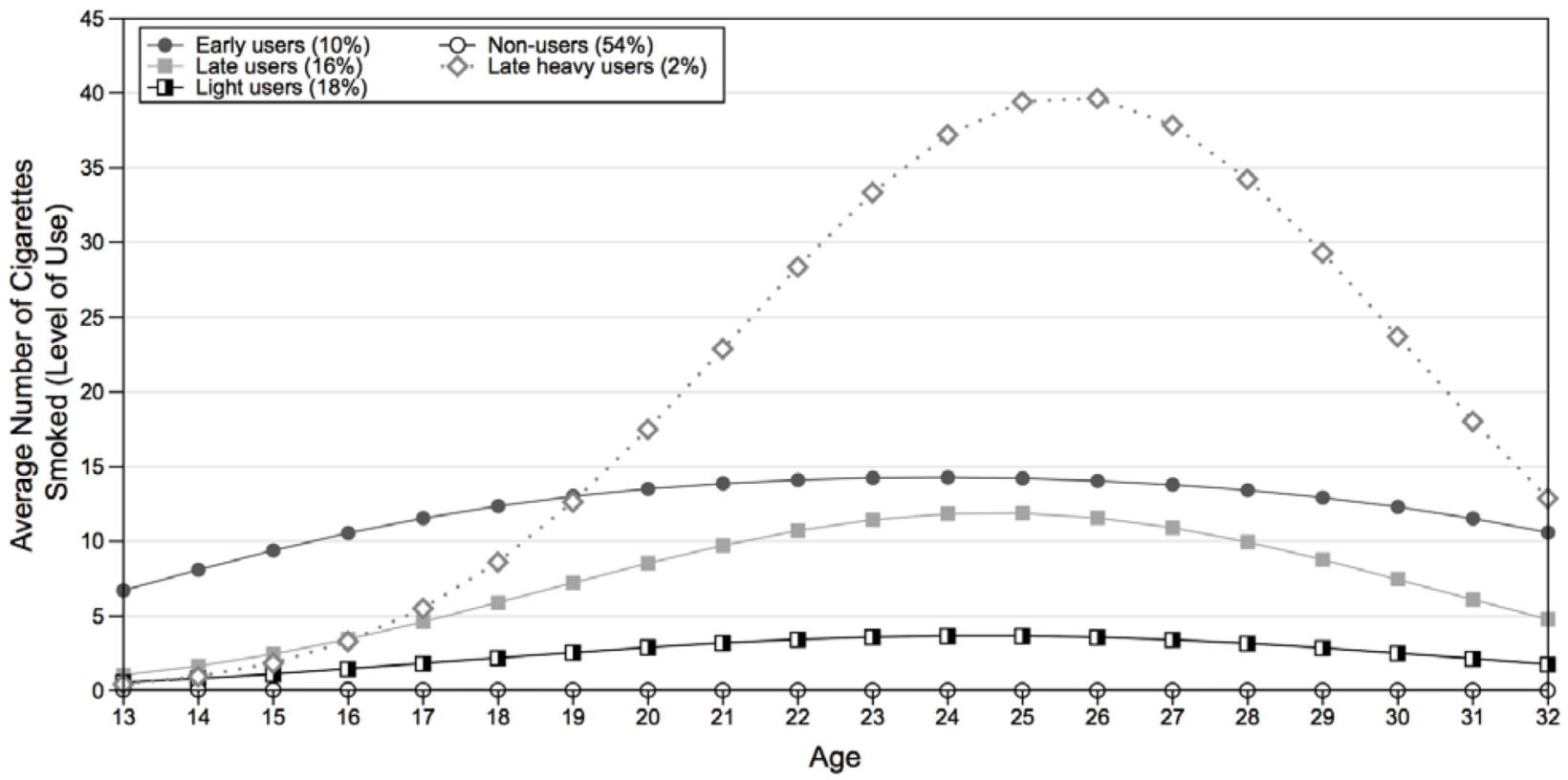

Figure 3.

Estimated mean number of cigarettes smoked for each of the five smoking typologies. 


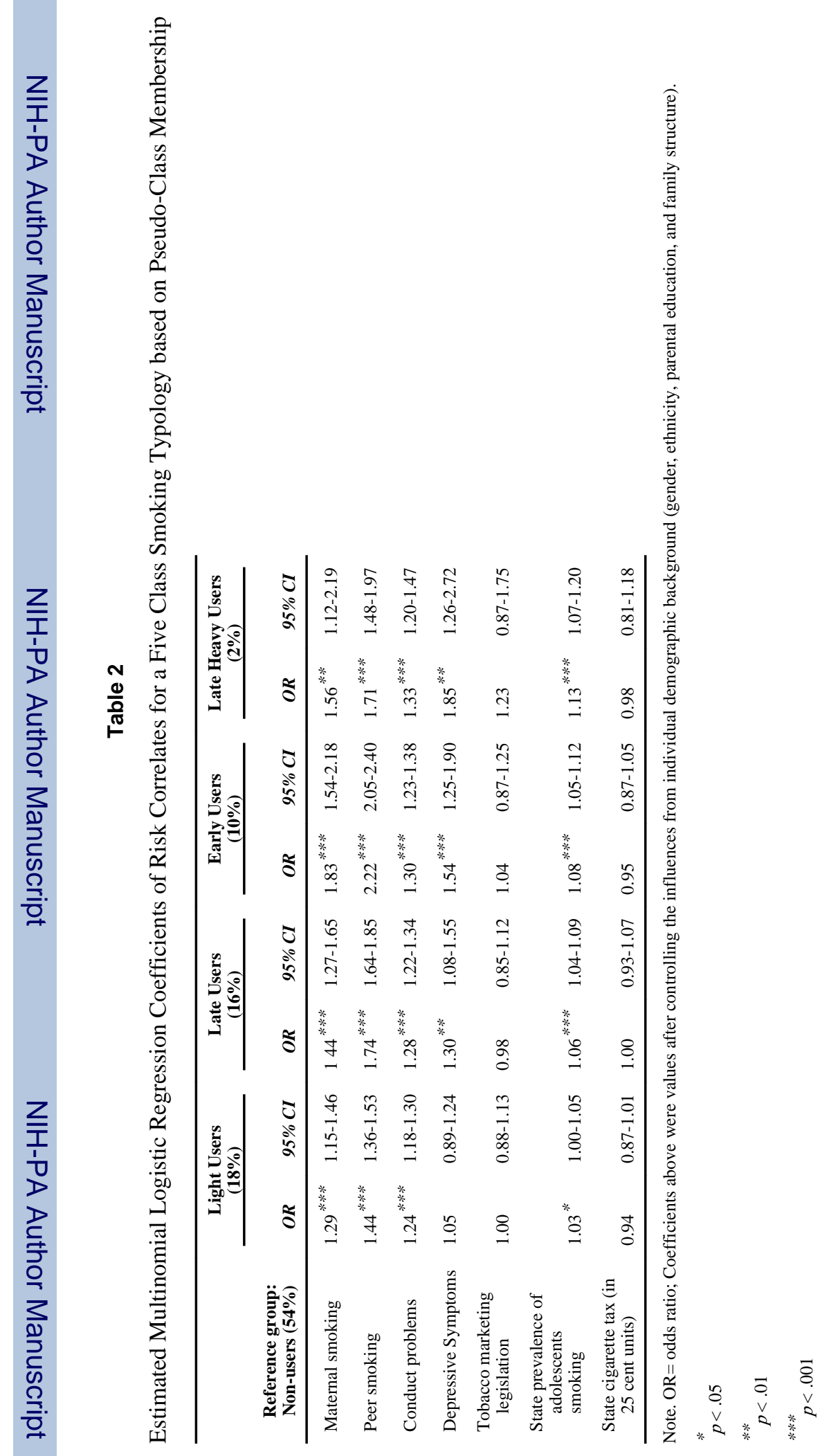

Drug Alcohol Depend. Author manuscript; available in PMC 2014 September 01. 